\title{
Hibridación y mestizaje de imaginarios en la historieta mexicana Huicalo
}

\section{Hybridization and miscegenation of imaginaries in the Mexican comic Huicalo}

\section{Sarahi Isuki Castelli Olvera}

Benemérita Universidad Autónoma de Puebla (México)

Sarahi Isuki Castelli Olvera es doctora en Ciencias Sociales, por parte de la Universidad Autónoma del Estado de Hidalgo. Es profesora investigadora de la Facultad de Comunicación en la Benemérita Universidad Autónoma de Puebla. Su línea de investigación es la cultura visual en la gráfica contemporánea, por lo que sus investigaciones están orientadas a los temas relacionados con cultura visual, arte contemporáneo, cómic japonés e historieta mexicana. Entre sus últimas publicaciones destacan los siguientes títulos: «Entre la tercera máquina y la bestia: Representación de la computadora y tecnologías en el manga $X$ de CLAMP», "Referentes iconográficos de $X$, un manga posmoderno: entre el apocalipsis y el yin yang», en la revista Estudios de Asia, del Colegio de México; «La introducción e influencia del manga en México: El caso de Lorena Velasco Terán y DREM», en la revista española CuCo, Cuadernos de Cómic y "New Age Elements in the CLAMP's Manga X», en la revista Jangwa Pana, revista de la Facultad de Humanidades de la Universidad de Magdalena. Es candidata al sistema nacional de investigadores.

Fecha de recepción: 27 de agosto de 2019

Fecha de aceptación definitiva: 16 de noviembre de 2019 


\title{
Resumen
}

En este artículo, examinamos la manera en la que los elementos del manga japonés, se adaptan en la historieta mexicana Huicalo (2014), creada por Emma Delgado Domínguez. Huicalo retoma elementos de la narrativa cross media, los cuales adapta a una historia con temas locales, en los que la figura de la muerte mezcla elementos procedentes de diversas tradiciones religiosas. Esta propuesta, basada metodológicamente en el paradigma de inferencias indiciales, se sostiene con teorías de mestizaje e hibridación cultural, para analizar los procesos en los que los imaginarios se mezclan y resignifican en un producto de la cultura popular contemporánea.

Palabras clave: Hibridación, Huicalo, Kimil, muerte, Shinigami

\begin{abstract}
In this article, we examine the way in which the elements of the Japanese manga are adapted in the Mexican comic Huicalo (2014), created by Emma Delgado Domínguez. Huicalo takes up elements of the cross media narrative, which adapts to a story with local themes, in which the figure of death mixes elements from various religious traditions. This proposal, based methodologically on the paradigm of indicial inferences, is supported by theories of miscegenation and cultural hybridization, to analyze the processes in which the imaginary are mixed and resignified into a product of contemporary popular culture.
\end{abstract}

Keywords: Death, Hybridization, Huicalo, Kimil, Shinigami ${ }^{1}$

\section{Cita bibliográfica}

Castelli Olvera, S. I. «Hibridación y mestizaje de imaginarios en la historieta mexicana Huicalo», en CuCo, Cuadernos de cómic, n.o 13 (2019), pp. 27-54.

\footnotetext{
${ }^{1}$ Trad. Sarahi Isuki Castelli Olvera, Benemérita Universidad Autónoma de Puebla.
} 


\section{Introducción}

Huicalo es una historieta mexicana autoconclusiva, creada por la artista mexicana Emma Delgado Domínguez, MemaInc, y publicada en 2014 en la revista Doon Magazine. En este artículo, argumentamos que dicha historieta hibrida elementos del manga japonés en dos aspectos: formato e imaginarios mágico-religiosos; en estos últimos, la figura de la muerte se crea teniendo como concepto atractor al psicopompo. Basamos nuestro argumento en lo siguiente: primero, la historieta hibrida las convenciones gráficas del manga japonés y su estructura se basa en la narrativa reticular centralizada, la cual tiene como base un texto parental, con sucesivas versiones alternas. Segundo, se observa la hibridación y mestizaje ${ }^{2}$ de temas mágico-religiosos en actantes como Kimen y Kimil, quienes tienen como atractor al psicopompo, del cual deriva el arquetipo de la muerte personificada. Tercero, el proceso de hibridación temático se lleva a cabo por medio de puntos de traslape y convergencia entre los diversos imaginaros del psicopompo.

En este artículo nos adherimos al paradigma de inferencias indiciales propuesto por Carlo Ginzburg, ${ }^{3}$ para quien los detalles aparentemente menos importantes abren la vía a realidades más complejas presentes en la fuente primaria estudiada, a las cuales tendremos acceso mediante un análisis de la imagen, basado en la identificación de referentes históricos e iconográficos de esta historieta. Metodológicamente, el análisis implica tres aspectos: la descripción de la imagen, elegida por condensar elementos constitutivos de la fuente, su correspondiente rastreo de referentes iconográficos, históricos y culturales, y el análisis del proceso por medio del cual la hibridación y mestizaje se llevan a cabo.

$\mathrm{El}$ análisis se sostiene, a partir de dos tipos de herramientas teóricas: las básicas sobre teoría de la hibridación y mestizaje, que fungen como el aspecto fundamental para analizar la fuente primaria, ya que explican los elementos primordiales del proceso de hibridación; aquí retomamos los aportes de Néstor García Canclini y Serge Gruzinski. El resto de las herramientas teóricas sirven como apoyo para explicar la manera en la que el proceso de hibridación se lleva a cabo en Huicalo; a este tipo de propuestas pertenecen los imaginarios de Durand ${ }^{4}$ y la propuesta de media-mix, de Manuel Hernández-Pérez. ${ }^{5}$

\footnotetext{
2 En este artículo entendemos a la hibridación y al mestizaje como sinónimos, teóricamente, nos basamos en las propuestas de Serge Gruzinski y Néstor García Canclini.

${ }^{3}$ Ginzburg, C. Mitos, emblemas e indicios, morfología e historia. Barcelona, Gedisa, 1999.

${ }^{4}$ Durand, G. Las estructuras antropológicas de lo imaginario. Madrid, Fondo de Cultura Económica, 2008.

${ }^{5}$ Hernández-Pérez, M. Manga, anime y videojuego. Narrativa cross media japonesa. Zaragoza, Universidad de Zaragoza, 2017.
} 


\section{La gráfica de Huicalo}

Doon Magazines es una revista de publicación independiente que se emite en la ciudad de México desde 2011. El formato del número 2 del 2014 es de 14 x $20 \mathrm{~cm}$ aproximadamente, portadas a color e interiores en blanco y negro. Cada ejemplar narra nueve diferentes historias; la estructura y gráfica retoman las convenciones de creación del manga japonés, específicamente la forma de narrar. ${ }^{6}$ Su historia adapta temas y contextos locales.

Huicalo narra la historia de Kimen, un baakel que se dedica a transportar las almas de los muertos a sus hogares el día de muertos. ${ }^{8}$ En una ocasión, cuando está realizando su trabajo, se encuentra con el alma de una niña recién muerta, Aruba; ella quiere quedarse y visitar el altar que su madre le está haciendo, pero Kimen no la puede ayudar porque los muertos recientes son jurisdicción de Kimil. Kimen decide finalmente ayudar a Aruba a llegar al altar de su madre pero, en el camino, Kimil los persigue para reclamar el alma que le corresponde. Al final, los rezos de la madre de Aruba los protegen y pueden llegar sanos y salvos al altar. Lo primero que resalta en esta historia es el estilo de dibujo, semejante a las convenciones del manga japonés: dibujos estilizados, sencillos, expresivos, ojos que ocupan más de la mitad del rostro, nariz y bocas representadas mediante líneas simples, que permiten un máximo de expresividad con mínimos recursos; «los rostros minimalistas del shoujo y del shounen han sido concebidos a fin de facilitar al máximo la expresión gráfica de los sentimientos y las emociones inscritas en sus inmensos ojos redondos». ${ }^{9}$ También es patente, en el estilo de narración, el predominio de la imagen sobre el texto, la focalización interna y el movimiento subjetivo; aspectos que, si bien no son exclusivos del manga, sí resultan altamente característicos del mismo.

Una de las escenas más representativas de lo anterior se encuentra en la página 153 (FIG. 1.): compuesta por cuatro viñetas, las dos superiores ocupan todo el ancho de página y miden de cinco a seis centímetros de alto. Las dos inferiores dividen el ancho de página justo a la mitad. En la primera viñeta observamos a Kimen, sosteniendo a Aruba de la mano mientras corren, ella dice: «ii Whoaa!! ¿Y sabes a dónde vamos?»; ante la pregunta, él se detiene en la siguiente viñeta y ella choca contra él; varios signos de interrogación abundan en esta viñeta. En la viñeta inferior izquierda, Kimen se sostiene la barbilla con la mano derecha, pensativo; un globo con una

\footnotetext{
${ }^{6}$ Castelli Olvera, S. I. Entrevista realizada a Nicolás Magaña en la ciudad de México (23 de septiembre de 2016).

7 En maya baak, significa hueso. Diccionario básico Maya- español en Yucatán identidad y cultura maya, 2019. Disponible en http://www.mayas.uady.mx/diccionario/b maya.html.

${ }^{8}$ Del 31 de octubre al 2 de noviembre en México.

9 Bouissou, J. M. Manga. Historie et univers de la bande desinée japonaise. París, Philippe Picquier, 2010, p. 181.
} 


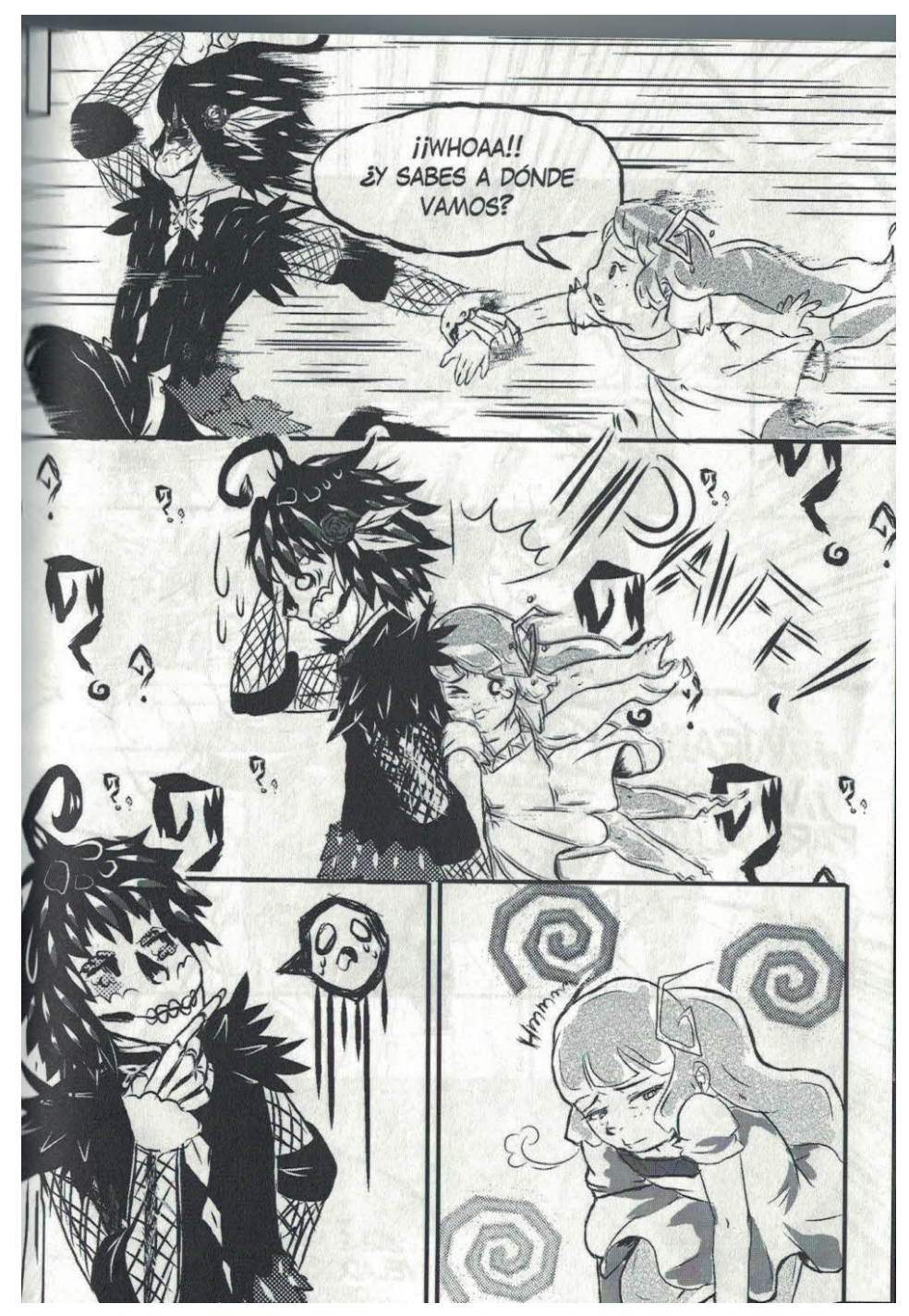

FIG. 1. Huicalo y las convenciones del manga (Delgado, 2014, p. 153)

especie de carita llorosa se conecta a él. Finalmente, a la derecha, Aruba, hincada, mira hacia otro lado, también pensativa. Esta página muestra un total predominio de la imagen sobre el texto, el cual solo se presenta en un globo y una onomatopeya en toda la página; «una de las premisas por las que se define el manga es, sin duda, por su naturaleza icónica, arraigada en su propio idioma», ${ }^{10}$ lo que agiliza la información y la lectura. ${ }^{11}$

10 Santiago Iglesias, J. A. Manga, del cuadro flotante a la viñeta japonesa. Pontevedra, Grupo de Investigación dX5 Digital y grafic art research, 2010, p. 134.

11 Idem. 
A lo largo de la historia, destaca la focalización desde dos ángulos: quien está contando la historia de Kimen y los emenata, propios de la focalización interna en el manga. Cuando hablamos de focalización nos referimos a «los conceptos de perspectiva o punto de vista» ${ }^{12}$ utilizados en el relato; en este caso, hay un narrador cuyos diálogos se distinguen por aparecer siempre en cartuchos negros. En el caso de la página seleccionada, no se representan cartuchos.

La focalización interna, por su parte, se refiere «a lo que el personaje realmente sabe y no aquello que vemos a través de él ${ }^{13}$ y en el caso de la página analizada, la encontramos de dos maneras: el movimiento subjetivo y los emenata. El movimiento subjetivo «consiste en la representación realista de los objetos y la desintegración de los fondos en forma de líneas» $;{ }^{14}$ en la primer y segunda viñeta de la imagen, el movimiento se acentúa con líneas cuando Kimen toma la mano de Aruba para correr, mientras sus figuras resaltan, claras, en dicho fondo. Por otro lado, el mismo golpe de Aruba con la espalda de Kimen, cuando se detienen, lleva algunas líneas para denotar las reminiscencias del movimiento.

En el manga «nos encontramos con frecuencia flores, estrellas y otros elementos del diseño del fondo, que muestran una experiencia subjetiva [pensamiento o emociones] del personaje» ${ }^{15}$; son recursos diseñados para acentuar la expresividad emocional «sin dejar que el texto devore al diseño». ${ }^{16}$ Estos elementos, comunmente llamados emenata, se observan de manera abundante en toda la gráfica de Huicalo; en esta imagen destacan en tres: signos de interrogación de diversos tamaños, una carita llorosa y las espirales tras Aruba.

\section{La estructura de Huicalo}

En este texto, entendemos el proceso de hibridación tal y como lo hace Néstor García Canclini, quien, desligándose de la noción de hibridez propia de la biología, entiende a la hibridación cultural como el proceso en el que «las estructuras o prácticas discretas, que existían en forma separada, se combinan para generar nuevas estructuras, objetos y prácticas». ${ }^{17}$ Dicho lo anterior, en este primer apartado, sostenemos que uno de los primeros puntos en los que se manifiesta la hibridación en Huicalo, es decir, en los que se fusionan diferentes estructuras para generar una nueva, es el formato de

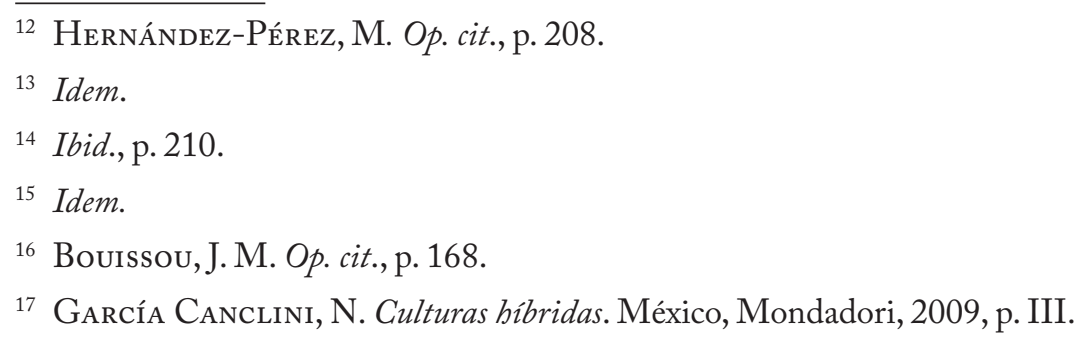


publicación, el cual asimila parte de la fórmula de comercialización y estructura del manga japonés; se fusionan el media mix por un lado, y las condiciones materiales y económicas de la autora por otro.

El media mix es una estrategia de comercialización que Manuel Hernández-Pérez identifica como propia del manga y sus productos relacionados, como el anime y los videojuegos. Se caracteriza por contar con un texto origen o parental, que usualmente es el manga del cual derivan secuelas, spin-off, anime, videojuegos y merchandising. El media mix, por lo tanto:

... designa la estrategia o conjunto de acciones por medio de las cuales las historias pueden llegar a un público determinado. Habitualmente, en el marco de la industria japonesa del entretenimiento, este conjunto de acciones incluye la adaptación entre lenguajes, siendo el manga y la televisión (anime), los principales medios empleados para una difusión que incluye los más diversos medios. ${ }^{18}$

Con la finalidad de que el producto logre expandirse y migrar a diversos medios, esta estrategia se vincula a un tipo de narrativa que Hernández-Pérez denomina cross media, la cual se caracteriza por narraciones que, como se dijo con anterioridad, deben contar con un texto parental, el cual se expande en sucesivas versiones y en diversos formatos (narrativa reticular centralizada). Suelen contar con personajes complejos, un tipo de gráfica específica y temas canónicos del mundo del manganime.

En Huicalo, Emma Delgado asimila la estructura narrativa reticular centralizada, la cual se caracteriza porque

... no adopta una clásica estructura (episódica) a lo largo de una única línea de tiempo, sino que se expande alrededor de unos eventos centrales o «núcleo de la narrativa», en forma de líneas relativamente autónomas. Al núcleo de estas narrativas se le conoce también como «texto o producto parental». ${ }^{19}$

El texto parental es Huicalo, objeto de análisis en estas páginas; posteriormente la autora publicó en 2015 el cómic corto Café de olla, en Devianart en inglés y en Facebook en la versión en español. Café de olla, compuesto por siete páginas en blanco y negro, narra una historia corta sobre Kimen y su pareja, Jela' An. La tercera versión es una precuela de Huicalo, Omitl, el cual inició su publicación en agosto de 2018 por medio de Facebook; en esta historia se narra las peripecias de Kimen durante su etapa escolar. Al ser un tipo de narrativa reticular centralizada, las historias son autónomas y uno puede leer Café de olla u Omitl sin necesidad de recurrir al texto parental que es Huicalo.

18 Hernández-PÉrez, M, Op. cit., pp. 52-53.

${ }^{19}$ Ibid., p. 127. 
Si bien en los planteamientos originales del crosss media el texto parental puede migrar del cómic a la animación, videojuegos o adquirir formatos diversos, esto no pasa en el caso de Huicalo por tratarse de un esfuerzo particular y no un producto de las grandes industrias culturales. Se observan procesos de adaptación, por parte de la autora, tanto del tipo de narrativa o cross media, como de la estrategia de mercado o media $m i x,{ }^{20}$ en el que los productos resultantes corresponden a su contexto y posibilidades. En este sentido, debemos destacar que, según Canclini, aunque la hibridación tiene muchos orígenes, a menudo surge de la creatividad individual, dada en condicionas párticulares de intercambios culturales.

A veces ocurre de modo no planeado, o resultado imprevisto de procesos migratorios, turísticos y de intercambio académico o comunicacional. Pero a menudo la hibridación surge de la creatividad individual y colectiva. No sólo en las artes, sino en la vida cotidiana y el desarrollo tecnológico. ${ }^{21}$

En este momento, es necesario destacar tres puntos en relación con el proceso de hibridación del formato en Huicalo: primero, que, como dice Canclini, los objetos o prácticas discretas, que se combinan para generar un nuevo producto, ya son, de por sí, producto de hibridaciones culturales. ${ }^{22}$ Tenemos que Emma se adaptó al formato que proponía la revista Doon en su momento, la cual, a su vez, muestra una marcada influencia de los mangash $i^{23}$ japoneses y las revistas misceláneas de historieta, propias de la época de oro en México. ${ }^{24}$ Segundo, Emma vive en un momento en el que ese ciclo de hibridación se acelera como producto de la flexibilización de fronteras y la intensificación de intercambio comercial al implantarse en México el tratado de Libre Comercio de América del Norte y el modelo neoliberal a partir de los noventa.

En el tercer punto, encontramos otro aspecto nodal en el proceso de hibridación: «Se busca reconvertir un patrimonio (una fábrica, una capacitación profesional,

${ }^{20}$ Además de la historieta, recientemente la autora ha comenzado con la producción de botones, llaveros y stickers, su idea es armar un catálogo para la venta de las mercancías.

${ }^{21}$ García Canclini, N. Op. cit., pp. V-VI.

${ }^{22}$ La historieta, el cómic y el manga, ya de por sí, son un producto híbrido por excelencia.

${ }^{23}$ Se trata de publicaciones periódicas «como enormes guías telefónicas impresas con muy mala calidad, preferentemente en blanco y negro sobre papel muy barato o reciclado, con un alta proporción de fibras de madera, que pueden ser de varios colores». Santiago Iglesias, J. A. Op.cit., p. 128.

${ }^{24}$ Abarca de 1934 a 1950 en México, durante este periodo el formato de las historietas era el siguiente: medían 28 por 43 centímetros los grandes, y 12 por 15 los chicos; su impresión era en una sola tinta, con frecuencia sepia o verde; usualmente se imprimían en medio tono y tenían tendencia al uso del collage. Bartra, A. «Piel de papel. Los Pepines en las educación sentimental del mexicano», en Hacia Otra Historia del arte en México, la fabricación del arte nacional a debate (1920-1950). México, CONACULTA, 2002, pp. 139-141. 
un conjunto de saberes y técnicas) para reinsertarlo en nuevas condiciones de producción y mercado». ${ }^{25}$ Esto tiene que ver con el proceso en el que la autora de Huicalo adaptó una estrategia de comercialización que originalmente proviene de compañías millonarias y que tiene alcances globales. Emma asimiló dicho formato y modo de circulación a sus condiciones particulares de capital económico y sus posibilidades de publicación: una revista de publicación gratuita por convocatoria como Doon, una serie de publicaciones como webcómic y la inversión de una cantidad de capital económico para reconvertirlo en capital cultural (stickers, calcomanías, llaveros, etcétera), que a su vez se convertirá en más capital económico.

\section{La interacción con el factor mágico: el psicopompo híbrido}

La historia de Huicalo se desarrolla en México, lo sabemos por la tradición a la que se alude (día de muertos), y el país se menciona a lo largo de la historia; sin embargo, el poblado en el que se llevan a cabo las acciones es impreciso. ${ }^{26}$ En Huicalo, un segundo punto en el que se presenta la hibridación son los diferentes imaginarios de la muerte, que se manifiestan en las figuras de Kimen y Kimil, actantes creados a partir de fuentes múltiples, que tienen como atractor ${ }^{27}$ a la de el psicopompo. Kimen está creado a partir de la mezcla gráfica y conceptual del shinigami ${ }^{28}$ las parcas y la catrina mexicana. Por su parte, Kimil es una deidad prehispánica maya que en la historia se encarga de transportar las almas de los muertos recientes. Dado que la figura del psicopompo es un elemento central en este texto, es menester destacar que lo definimos como una serie de figuras

que aparecen en innumerables mitologías y religiones a lo largo de la historia. Su principal responsabilidad o labor es la de acompañar a las almas de los recién fallecidos al más allá (siendo su destino final el cielo o el infierno, dependiendo de la cultura). El rasgo clave que los diferencia de las diversas figuras mitológicas que poseen relación con el más allá es que su función no es la de juzgar a la persona fallecida. Por el contrario, su papel primordial es el de proporcionar un paso seguro y acompañar durante la travesía a las almas entre los diferentes planos de existencia. ${ }^{29}$

${ }^{25}$ García Canclini, N. Op. cit., pp. V-VI.

${ }^{26}$ Los indicios apuntan a una zona del sur de México debido a las alusiones a la cultura maya.

27 Para Gruzinski, el atractor es el elemento que vincula «simpatías» aun entre los elementos más diferentes y lejanos; es un elemento aglutinante que permite de la hibridación o mestizaje.

${ }^{28}$ Dioses japoneses de la muerte. Tienen una existencia tardía en el folclore japonés.

${ }^{29}$ Valle Morán, M. «La figura del psicopompo en las prácticas y rituales contemporáneos de tránsito hacia la muerte», en XII Congreso español de sociología, 2016, p. 3. Disponible en https:// www.fes-sociologia.com/la-figura-del-psicopompo-en-las-practicas-y-rituales-contemporaneos/ congress-papers/2915/ 


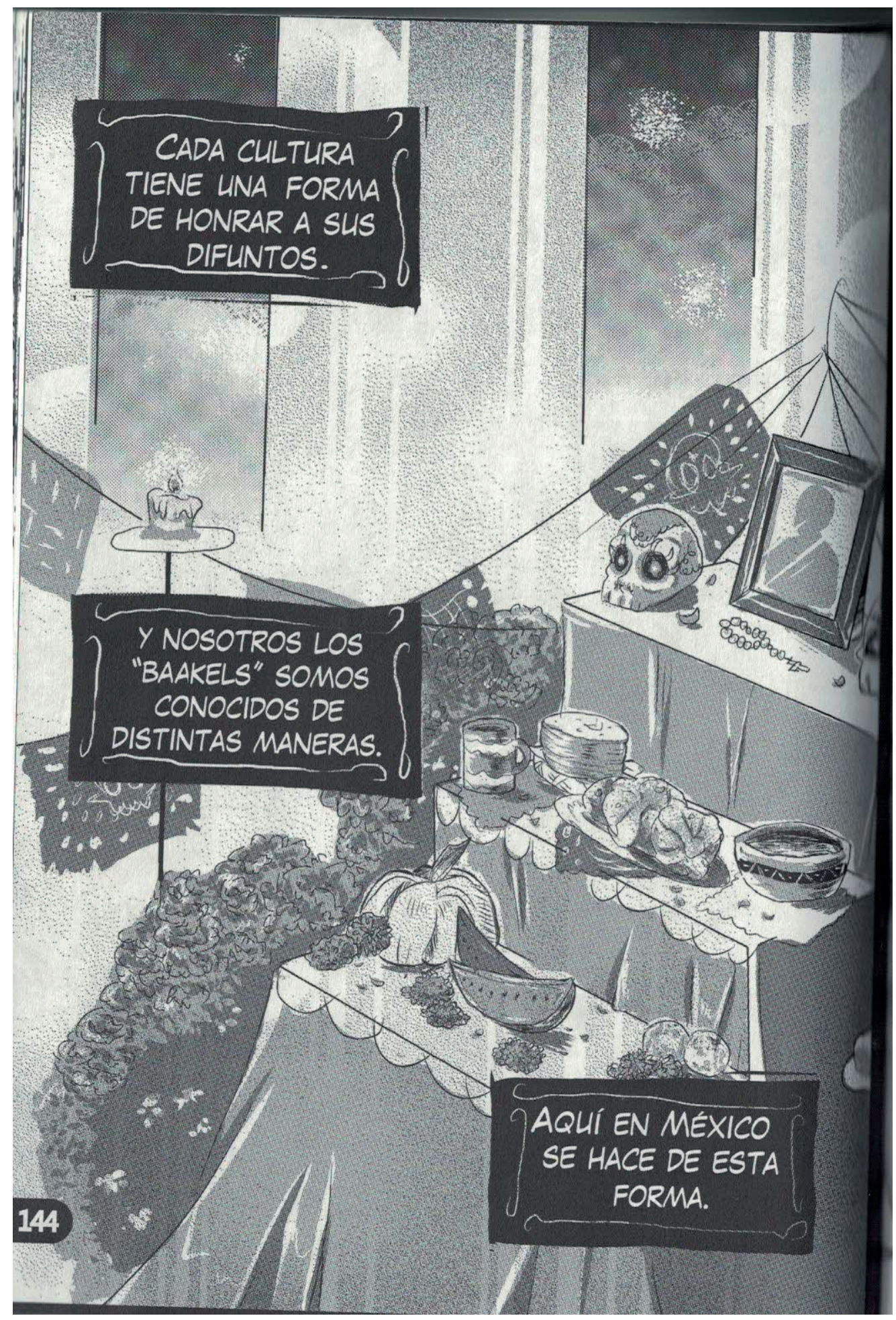

FIG 2. Kimen en Huicalo (Delgado, 2014, p. 144) 
Huicalo, en náhuatl, significa llevado o transportado. ${ }^{30} \mathrm{El}$ protagonista se define a sí mismo y a su familia como baakel, que en la historia son guías espirituales que se encargan de «dirigir las almas del otro mundo, hasta sus altares de muertos»; ${ }^{31}$ la representación e iconografía de Kimen le dan un aire de similitud a la de Jack, protagonista de la película The Nightmare Before Christmas; ${ }^{32}$ mientras Jack usa un frac cuyo cuello termina en una especie de picos y un murciélago en lugar de moño, Kimen usa una especie de chaleco cuyos hombros terminan en picos, moño rojo al cuello y una camisa que pareciera estar hecha con una red en la zona de las mangas, las cuales terminan en volantes con punta roma. El chaleco es negro, al igual que el pantalón entubado y roto que porta; lo anterior le da un aire visual que oscila entre la vestimenta de la tribu urbana gótica y el emo. Su cabello es degrafilado y su rostro está cubierto por una máscara blanca, decorada con líneas curvas de colores rojos y violetas.

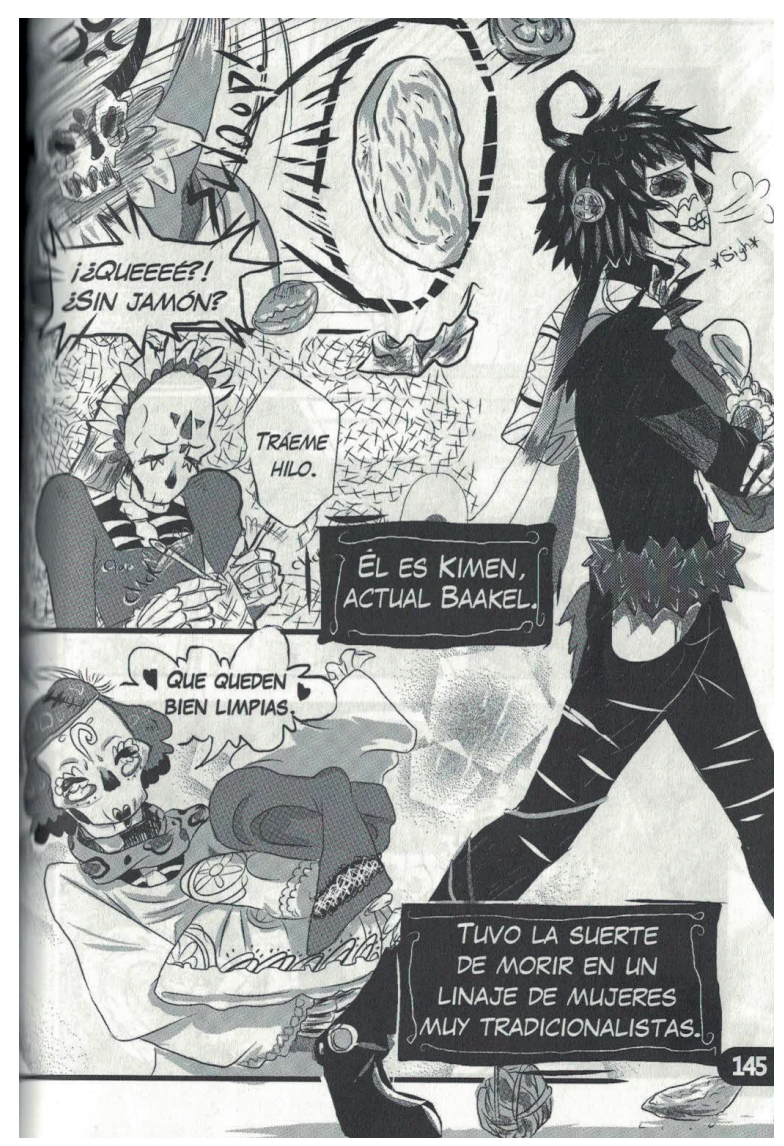

FIG 3. Kimen y su familia en Huicalo y las convenciones del manga (Delgado, 2014, p. 145)

${ }_{30}$ Véase http://www.vocabulario.com.mx/nahuatl/diccionario nahuatl 1.html

31 Delgado, E. Huicalo, en Doon Magazine, Ciudad de México, 2014, p. 143.

32 Burton, T. The Nightmare Before Christmas [Filme]. Walt Disney Pictures, 1993. 
Desde las primeras páginas, se condensa la imagen de Kimen, y su carácter de psicopompo. En la página 144 (FIG. 2) se representa un altar de muertos, que ocupa la mitad diagonal inferior derecha de dicha la página. El altar está compuesto por tres niveles: en el primero, se alcanzan a distinguir dos calaveras de azúcar que flanquean una fotografía, frente a la cual reposa un rosario. En el segundo nivel se observa una taza con líquido, que podría ser chocolate por su consistencia oscura, tortillas, pan de muerto y un plato con guisado. El último nivel tiene frutas: calabazas, sandías, guayabas y flores. Sobre el altar cuelga papel picado. Hay muchas flores en el costado izquierdo del altar y una vela que descansa en un candelabro de pedestal. El texto se desarrolla en tres cartuchos negro con letras en blanco, el primero dice: «cada cultura tiene una forma de honrar a sus difuntos»; continúa en el segundo: «y nosotros los baakels somos conocidos de distintas maneras». El tercer cartucho dice: «aquí en México se hace de esta forma». ${ }^{33}$

La página siguiente (FIG. 3) tiene una composición que divide la hoja por la mitad; en primer plano a la derecha se representa a Kimen de perfil y de cuerpo completo; él suspira, los cartuchos en negro dicen: «Él es Kimen, actual baakel / Tuvo la suerte de morir en un linaje de mujeres muy tradicionalistas». ${ }^{34} \mathrm{~A}$ la izquierda y en segundo plano, se observan tres viñetas que contienen cada una a tres esqueletos caracterizados como catrinas. La secuencia narrativa se desarrolla de arriba abajo y ocupan la mitad la página. En la primer viñeta se observa el cráneo de un esqueleto femenino; porta un sombrero y una vena se superpone sobre el mismo, para denotar enojo; las cuencas y la frente están decorados con figuras circulares. Ella arroja una especie de pan y una rebanada de jitomate mientra dice: «i¿Queeeé?! ¿Sin jamón?». En la segunda viñeta se representa otro esqueleto, con un vestido de hombros abombados y una diadema en la cabeza; este esqueleto, también femenino, está tejiendo y dice: «Traéme hilo». El último esqueleto, también femenino, tiene cabello corto y una tiara con una pluma sobre la cabeza, se trata de un peinado muy parecido al de una bailarina de charlestón, sostiene un montón de ropa y dice: «Que queden bien limpias». ${ }^{35}$

Estas imágenes permiten situar la historia temporalmente en el día de muertos, y destacar el hecho de que los baakel representan a seres que cumplen con la función de guías espirituales. Kimen y el resto de su familia mezclan referentes procedentes de diversos contextos: a nivel temático. destacan el shinigami japonés y las parcas occidentales; a nivel gráfico, encontramos a la catrina y las calaveras de azúcar que se fabrican en México el día de muertos.

En la historia, Kimen y los otros baakels guían el almas de muertos. Con esta tarea hay un par de referentes históricos y culturales inmediatos. Por el tipo de historia y grá-

\footnotetext{
33 Delgado, E. Op. cit., p. 144.

${ }^{34}$ Ibid., p. 145.

35 Idem.
} 
fica de Huicalo, primero tendríamos al shinigami japonés: un ser mitológico que tuvo surgimiento tardío en su cultura de orígen. Se trata de «un ser del folclore japonés que no aparece en los escritos clásicos de Japón hasta mediados del período Edo» (16031868), donde surge el término en obras de la literatura clásica japonesa como Los amantes suicidas de Sonezaki. ${ }^{36}$ Una ilustración de la configuración termprana de esta entidad se puede observar en el Ehon Hyaku Monogatari (Picture Book of a Hundred Stories), edición ilustrada por el artista japonés Takehara Shunsensai en 1841; en ella se observa al shinigami en posición de tres cuartos, el ceño parece fruncido, cabello en punta y, en la boca pequeña, unos colmillos. ${ }^{37} \mathrm{La}$ concepción original de shinigami no parecía adjudicarle la función de un psicopompo; más bien se trataba de espíritus de muertos que podían incitar a las personas a cometer suicidio; ${ }^{38} \sin$ embargo, «en otras épocas de la historia de Japón, los shinigami también se encargan de transportar las almas hasta el lugar que les corresponde, aunque en ocasiones sea de manera forzada». ${ }^{39}$

La idea original del shinigami se transforma con el contacto con otras culturas y tradiciones, de tal forma que cuando se representan en el manga, estos seres pueden tener matices, ya que «a veces la figura del Shinigami en el manga se ha entremezclado con la de otros seres de la mitología occidental que también se encargan de llevar las almas al lugar que les corresponden». ${ }^{40}$ En el imaginario del manga y anime, los shinigamis son dioses de la muerte japoneses.

Kimen, guarda más semejanza con la representación que se hace del shinigami en el manga y anime Death Note, ${ }^{41}$ particularmente por la indumentaria del personaje de Ryuk, a quien se representa como una especie de gigante con piel gris, ojos rojos y colmillos puntiagudos. Conceptualmente, la similitud con el shinigami se da no solo debido a la tarea de acarrear almas, sino por su carácter múltiple, ya que tanto los baakels como los shinigamis son más de uno: «los mensajeros de la muerte japoneses son numerosos, equilibrando su poder y fuerza con sus iguales o con otras deidades que pueblan el imaginario nipón». ${ }^{42}$

Derivado de su relación conceptual con los shinigamis, encontramos una segunda fuente de la que la representación de Kimen parece beber: las parcas, quienes tienen

\footnotetext{
36 Monzaemon citado por Moreno Griñón, S. «Death Note: el concepto de Shinigami y la pena de muerte en Japón», en Brumal, revista de investigación sobre lo fantástico, vol. vI, n. ${ }^{\circ} 1$ (2018), p. 251.

37 Véase https://pulverer.si.edu/node/972/title/1/12

38 Valle Morán, M. Op. cit.

39 Moreno Griñón, S. Op. cit., p. 251.

${ }^{40}$ Idem.

${ }^{41}$ El manga se publicó por primera vez en México por parte de Editorial Vid en 2007, y en 2015 por Panini.

${ }^{42}$ Moreno Griñón, S. Op. cit., p. 254.
} 
antecedente en las Moiras griegas, tres divinidades relacionadas con los alumbramientos, ya que «presiden los nacimientos de los bebés humanos y también de los dioses [...] están implícitamente ligadas a aspectos como los de la fertilidad y la fecundidad». ${ }^{43}$ Con los romanos, se lleva a cabo una reelaboración de las moiras, que se convierten en las parcas, tres hermanas hilanderas (Nona, Décima y Morta) que representaban el nacimiento, la vida y la muerte.

En Huicalo, las funciones de los baakels no parecen tan amplias, no se relacionan con los nacimientos o el destino de los vivos; sin embargo, en la precuela de Huicalo, Omitl, se presenta la ficha de los datos de Kimen, y este aparece bajo la clasificación de «Muerte», lo cual le daría atribuciones más amplias de las que presenta en Huicalo.

El tercer referente presente en la representación de Kimen es la catrina, más específicamente su versión masculina: el catrín. Iconográficamente, su principal similitud es el frac con moño que ambos portan; sin embargo, la autora define a Kimen como un «catrina boy» en una de sus ilustraciones de Devianart; ${ }^{44}$ y más tarde, en una publicación en Facebook, enfatiza que la catrina es su principal referente. ${ }^{45}$

La catrina, célebre representación realizada por José Guadalupe Posada,

es una publicación de la imprenta de Antonio Vanegas Arroyo que circuló en 1913 con el título de Remate de calaveras alegres y sandungueras. Las que hoy sin empolvadas garbanceras pararán en deformes calaveras. Esta publicación es una hoja volante que tiene unos versos dedicados a la obsesión de las empleadas domésticas, es decir, las garbanceras, para ataviarse $y$ maquillarse pretenciosamente. ${ }^{46}$

Con influencia de las Vanitas, ${ }^{47}$ esta calavera pretende hacer énfasis en la transitoriedad y lo efímero de los placeres mundanos de la vida. Catrina es el nombre que le asignó Diego Rivera a esta publicación de Posada, años después, cuando la retomó

43 Pérez Miranda, I. «Hijas de la noche II: El destino de las parcas entre el pasado y el presente», en Arys, n. 8 (2009-2010), pp. 144.

${ }^{44}$ La traducción sería «catrín», pero la autora hace el comentario en inglés. Véase en https://www. deviantart.com/memainc/art/Catrina-waiter-728907993

45 Véase https://www.facebook.com/memainc.delguez/photos/pcb.2290118731231257/2290115944 564869/?type $=3 \&$ theater

46 Camacho Morfín, T. y González Manrique, M. J. «Las calaveras de Posada. De las Danzas de la muerte a las Vanitas», en Trayectos, usos y significaciones de la imagen y la memoria. Puebla, Benemérita Universidad Autónoma de Puebla, 2017, pp. 172-173.

47 Son un tipo de pintura en la que sirve para recordar al espectador que los placeres y riquezas del mundo son fugaces, pasajeros, y que la muerte es lo único seguro. LABARGA, F. «Reseña de Vanitas» en Retórica visual de la mirada de Luis Vives-Ferrándiz Sánchez. Anuario de Historia de la Iglesia, vol. 21, (2012), p. 626. 
para satirizar a las personas elegantes y de alcurnia que tenían el poder. ${ }^{48} \mathrm{~A}$ Kimen su autora lo presenta con referencias directas al catrín, principalmente por la indumentaria y los adornos de su máscara; esto hace que, al mezclarse con los referentes anterioremente señalados, la imagen de Kimen juegue con aspectos de la vestimenta que portan tanto el catrín, Jack y Ryuk, sin perder la originalidad. Por otra parte, la máscara remite a las calaveras de azúcar que se fabrican en México, a modo de alfeñique ${ }^{49}$ durante los días de muertos, las cuales son blancas y se decoran con betún y colores vegetales.

Hasta aquí se presentan los elementos que construyen a Kimen, los cuales se mezclan en razón de la historia que se cuenta en Huicalo: tanto el shinigami, como la parca y la catrina-calavera de azúcar, se aglomeran en este personaje que tiene el tema de la muerte como conductor en tanto se trata de psicopompos cuya función es acompañar a los muertos; sin embargo, la mayoría de ellos presentan cierto desprendimiento de su contexto original debido a que solo se retoma la gráfica y el tema, de manera superficial, para adaptarlos a la historia y al contexto particular que se retrata.

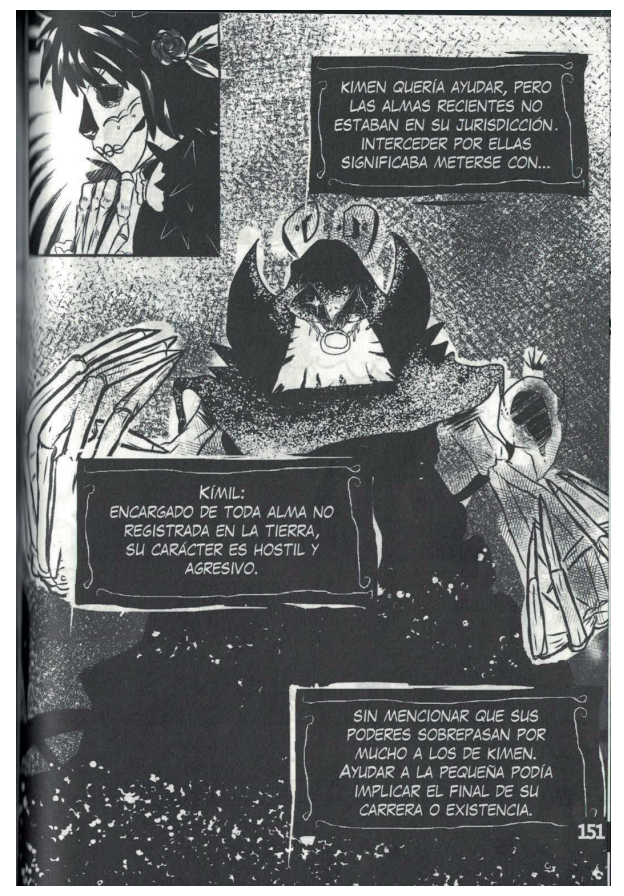

FIG 4. Kimil en modalidad antropomorfa (Delgado, 2014, p. 151)

${ }^{48}$ Guerrero Viguri, R. «Catalina Creel, la versión contemporánea de la Catrina», en Balajú, Revista de cultura y comunicación, n. ${ }^{\circ} 3$ (2015), pp. 62-71.

49 «El alfeñique es una mezcla de azúcar, clara de huevo, gotas de jugo de limón y una planta llamada chaucle o chautle (blatia campanulata)». en Regeneración (1 de noviembre de 2016). Disponible en https://regeneracion.mx/breve-historia-de-las-calaveritas-de-azucar/ 
El segundo tipo de psicopompo presente en Huicalo es la deidad de orígen maya Kimil, quien en esta historia cumple la función de adueñarse de las almas recientes, a quienes no se les permite asistir a los festejos del día de muertos, y cuyo destino final no queda claro. Kimil toma dos formas a lo largo de la narración: una antropomorfa y otra ofidia. La primera es la de un ser al que nunca se le ve el rostro debido a que porta una especie de túnica larga y negra, con capucha y hombreras que terminan en picos; en su pecho destaca una especie de medallón redondo. En lugar de rostro, a Kimil solo se le distingue una estrella brillante que hace referencia a uno de sus ojos; tiene antenas en su cabeza (o capucha) y sus manos, esqueléticas, se suelen representar hacia el frente sosteniendo una especie de pedernal (FIG. 4).

En su imagen en la página 151, en tres cartuchos negros, el narrador explica: «Kimen quería ayudar pero las almas recientes no estaban en su jurisdicción. Interceder por ellas significaba meterse con... / ... Kimil: encargado de toda alma no registrada en la tierra, su carácter es hostil y agresivo, / sin mencionar que sus poderes sobrepasan por mucho a los de Kimen. Ayudar a la pequeña podía implicar el final de su carrera o existencia». ${ }^{50}$ Esta imagen corresponde con el primer tipo de forma que toma Kimil en el relato, y su relación gráfica más evidente es la de la personificación de la muerte en occidente, lo que se observa en dos aspectos principales: la túnica negra (sayal) y su representación esquelética con las manos extendidas.

El segundo referente gráfico al que remite Kimil en esta forma es la de Wiseman, un villano del anime Sailor Moon $R,{ }^{51}$ al cual se representa sentado, con las piernas cruzadas, cubierto, casi por entero, con un manto gris que deja al descubierto la zona del rostro y torso. Con las manos al frente, sostiene una esfera para ver el futuro. La representación de Kimil en Huicalo guarda similitudes con Wiseman, en aspectos que van desde la postura y la gráfica, al concepto vinculado con lo negativo, ya que ambos fungen como oponentes del protagonista del relato al que pertenecen.

La segunda forma que toma Kimil es la ofidia. Una de las imágenes en donde su representación es más clara la observamos en la página 160 (FIG. 5). En ella, se observa cómo Kimen y Aruba huyen de él; en la primera viñeta de la parte superior aparecen Kimen y Aruba en primer plano, de espaldas. Frente a ellos, Kimil les gruñe y las líneas cinéticas generan la ilusión de que dicho ser se cierne sobre ellos. En la segunda viñeta, se observa a Kimen sentado en el piso, con las manos apoyadas hacia atrás, mientras Aruba se esconde tras él. Frente a Kimen está Kimil, de perfil con las fauces abiertas, la lengua bífida goteando saliva. La parte inferior de su mandíbula, al igual que el resto del cuerpo, es negra y escamosa. Las fosas nasales se enroscan como especie de caracol, y el rostro y la melena son blancos; esta última se representa como

50 Delgado, E. Op. cit., p. 151.

${ }^{51}$ Transmitida en México por TV Azteca entre 1996 y 1998. 
especies de escamas que sobresalen de la cabeza del ofidio. Kimil no tiene ojos cuando toma esta forma.

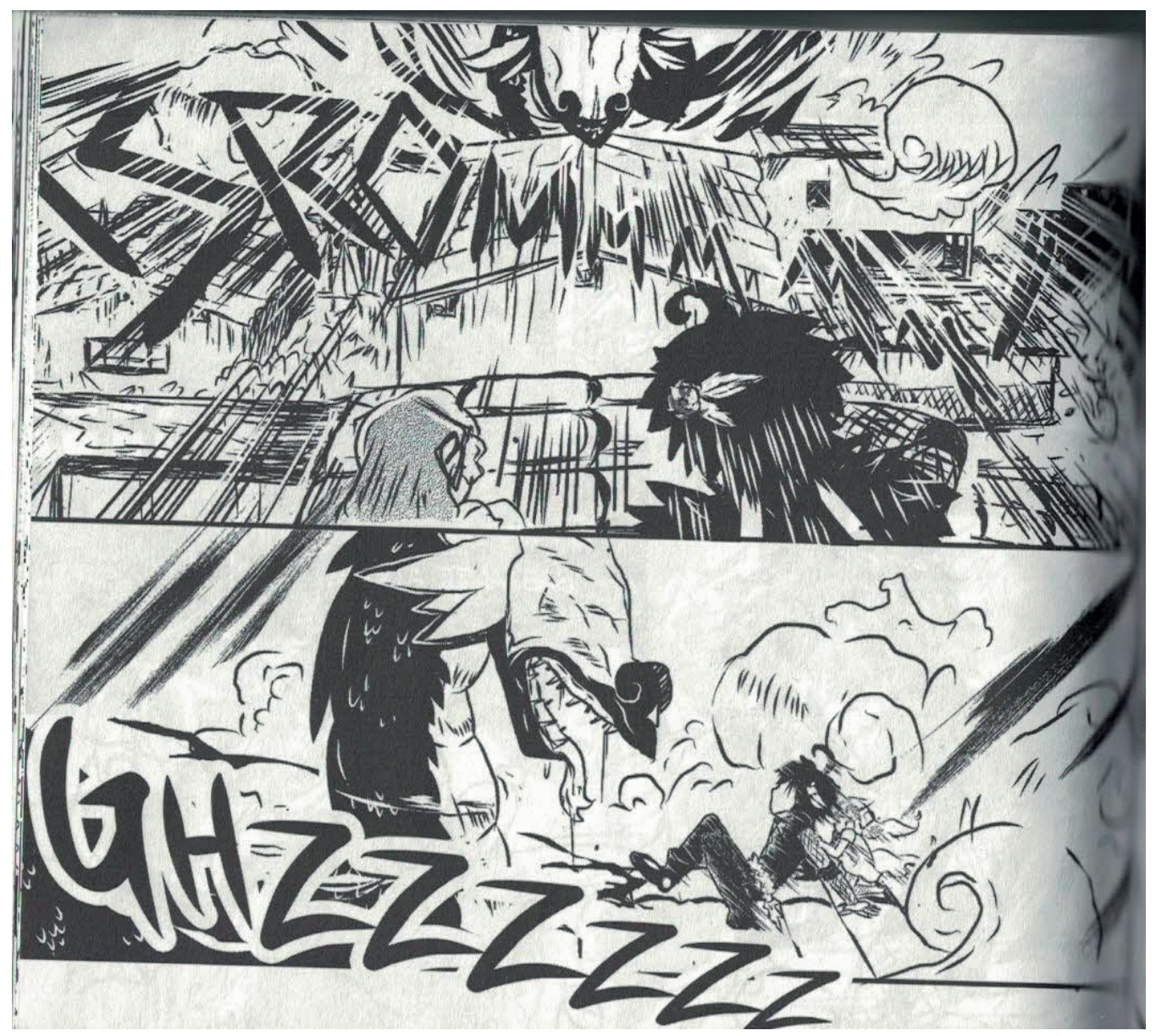

FIG 5. Kimil en modalidad ofidia (Delgado, 2014, p. 160)

Hay tres referentes principales en relación a esta segunda forma de Kimil: a nivel gráfico encontramos al ofidio prehispánico ${ }^{52} \mathrm{y}$ al dragón chino-japonés; ${ }^{53}$ a nivel conceptual ubicamos a Kimil como deidad de la muerte entre los mayas prehispánicos.

En Huicalo, el Kimil ofidio es prácticamente una serpiente que se asemeja a la representación de Quetzalcóatl en su advocación de serpiente emplumada. La manera en la que Kimil se representa, con las fauces abiertas y la lengua bífida al descubierto, se asemeja un poco a la representación que se hace de Quetzalcóatl en bajorrelieve sobre

52 De la Garza, M. «El dragón, símbolo por excelencia de la vida y muerte entre los mayas», en Estudios de cultura maya, vol. 20 (1999), pp. 179-207.

53 Zнао, Q. A study of dragons, East and West. Nueva York, Peter Lang, 1992. 
un templo en Xochicalco, ${ }^{54}$ particularmente porque, al igual que el Kimil de Huicalo, Quetzalcóatl aparece semierguido, con las fauces abiertas, y los colmillos y la lengua bífida al descubierto. Otra similitud gráfica que presenta Kimil en su forma serpentina con Quetzalcóatl es la melena que ambos tienen; en el caso de Kimil, parecen especies de escamas blancas alrededor de su cabeza, similares a las de las esculturas del templo de Quetzalcóatl en Teotihuacán. ${ }^{55}$

A Kimil, en su forma serpentina, nunca lo vemos completo, y lo que se alcanza a distinguir en ocasiones se asemeja a un dragón oriental y en otras simplemente parece una serpiente. Un aspecto importante a considerar es que, en esta forma, a Kimil tampoco se le distinguen ojos, aunque parece ver o fijarse directamente en Kimen y Aruba como presas.

El Kimil ofidio guarda correspondencia con lo que sostiene Mercedes de la Garza en relación con las entidades que considera dragones mesoamericanos:

... llamamos dragón a este ser fantástico porque combina rasgos de diversos animales, fundamentalmente serpiente y ave, predominando el carácter serpentino [...]. El término proviene del sustantivo latino dracon, «serpiente», que deriva a su vez del verbo dercomai, el cual define la intensidad de la mirada, fija y paralizante de la serpiente. ${ }^{56}$

Esta entidad prehispánica tiene un concepto complejo en su cultura originaria, lo que se observa en la presencia de elementos de animales terrestres y celestes: «... el dragón es, así, un ser sagrado múltiple y polivalente. Su carácter celeste se expresa con alas y plumas; el terrestre con símbolos de vegetación y rasgos de cocodrilo, y el infraterrestre con huevos y otros símbolos de muerte». ${ }^{57}$

Más que complejo y polivalente, el dragón Kimil de Huicalo está ligado a la parte terrestre, en la cual es «aquél que integra en sí mismo el inframundo», ${ }^{58}$ ya que se trata de un dragón-tierra-cocodrilo.

El segundo referente de la gráfica de Kimil en su forma ofidia es el dragón oriental, al cual Zhao Qiguang define de la siguiente forma: «cabeza de camello, ojos de demonio, cuello de serpiente, abdomen de almeja, las escamas de una carpa, las garras de serpiente, patas de tigre y orejas de vaca». ${ }^{59}$ Entre Kimil y este dragón la convergencia

\footnotetext{
54 Véase https://mapio.net/pic/p-25977801/

55 Véase https://www.artehistoria.com/es/obra/templo-de-quetzalcóatl-teotihuacan-méxico-detalle

56 De la Garza, M. Op. cit., p. 180.

57 Ibid., p. 184.

58 Idem.

59 Z $\mathrm{HAO}$, Q. Op. cit., p. 19.
} 
se da a partir de dos principales elementos: la melena, que en el dragón chino varía de posición de acuerdo con la dinastía, y la forma serpentina que se proyecta en el espacio; aunque el dragón chino-japonés se eleva por el cielo y el Kimil de Huicalo se mueve a nivel de la tierra. Pese a que el dragón oriental tiene, conceptualmente, puntos de similitud con el dragón prehispánico que describe de la Garza, ${ }^{60}$ el Kimil de Huicalo se desprende del carácter dual y su simbolismo se maneja a nivel terrestre, nocturno e inframundano; algo más similar a la idea negativa del dragón occidental, ya que «en el mundo europeo el símbolo del dragón tiene, ante todo, una significación maléfica, ya que es tanto el caos promigenio como el monstruo que aparecerá como la fuerza destructora en el Apocalipsis». ${ }^{61} \mathrm{Al}$ igual que el dragón occidental, Kimil representa la fuerza maligna que Aruba y Kimen deben derrotar para salir victoriosos; vemos que las similitudes con los dragones prehispánico y oriental son, ante todo, gráficas.

A nivel conceptual, el referente principal del Kimil de Huicalo, independientemente de su forma antropomorfica u ofidia, es Kimil, deidad maya prehispánica de la muerte, que en su contexto original tiene carácter dual. Alberto Morales Damián expresa que "posee un caracter andrógino; es masculina al exponer su falo y derramar su semen garantizando la lluvia, es femenina al abrir sus piernas para parir el maíz». ${ }^{62} \mathrm{En}$ los códices prehispánicos, su imagen se identifica por su cráneo con un globo ocular a semejanza a un cascabel y «por su columna vertebral y costillas descarnadas». ${ }^{63}$

El Kimil de Huicalo no retoma nada de la gráfica original del Kimil prehispánico maya, tampoco el concepto dual; solo está su referencia como deidad de la muerte. En su carácter de psicopompo, este Kimil se asemeja más al que describe Olivier Le Guen en relación a los mayas yucatecos contemporáneos, cuyas prácticas funerarias analizó en Quintana Roo. Le Guen expresa que, dentro de esta población, se cree que

después de la muerte el pixan o «alma» se separa del cuerpo. Y este es el componente de la persona que va a sobrevivir y el que regresará a la tierra durante los rituales. Parece que el pixan conserva las características de la persona, tales como su memoria y su personalidad, aunque se alteran con su nuevo estado y se van perdiendo con el tiempo. ${ }^{64}$

${ }^{60} \mathrm{Al}$ igual que el prehispánico, el dragón oriental también tiene un carácter dual, particularmente el tipo de dragón conocido como shenlong, ya que tiene la facultad de formar la lluvia, tornados, ciclones y trombas. Ibid., p. 103.

${ }^{61}$ De la Garza, M. Op. cit., p. 182.

${ }^{62}$ Morales Damián, M. A. «Muerte fecunda. Imágenes de Ah Kimil en el Códice Madrid», en Congreso Internacional Imágenes de la Muerte (Salta, Agosto 2014). Argentina, Universidad Nacional de Salta, 2014, p. 15.

63 Ibid., p. 3.

${ }^{64}$ Le Guen, O. «Ubèel Pixan: el camino de las almas. Ancestros, familiares y colectivos entre los mayas yucatecos», en Península, vol. 3, n. ${ }^{\circ} 1$ (2008), p. 86. 
Aruba es un pixan de muerte muy reciente, lo que genera dos cosas: por un lado, conserva sus características físicas y su memoria; por otro, le imposibilita quedarse a disfrutar del altar que su madre hizo en su honor; esto último se entiende porque los mayas yucatecos piensan que, durante el primer año de muerte, al alma no se le permite alimentarse: «en Kopchén se dice que el alma no puede alimentarse durante el primer Hanal pixan a un año de su muerte, y tampoco se le invoca por su nombre». ${ }^{65} \mathrm{El}$ Hanal pixan parece ser equivalente al día de muertos entre los mayas: «las ceremonias del hanal pixan (literalmente «la comida de las almas»), se desarrollan en dos partes: primero son recibidas las almas de los niños durante la noche del 31 de octubre y el día siguiente, 1 de noviembre, las de los adultos». ${ }^{66}$

En Huicalo, Aruba rompe las reglas desde el momento en que decide quedarse y disfrutar de su altar, y hace que Kimen las transgreda también. Desde que Aruba es jurisdicción de Kimil, este sale a reclamarla, pero los rezos de la madre de Aruba los protegen y ella puede llegar a su altar. Que Kimil se encargue de las almas recientes no parece ser una creencia presente entre los mayas yucatecos contemporáneos que estudió Le Guen, pero sí lo conciben como un tipo de psicopompo que guía a las almas a la tierra durante el Hanal Pixan:

Cuando las almas regresan a la tierra no recorren los espacios libremente, siempre son acompañadas/vigiladas por lo que se denomina un "pasador de almas», cuyas ofrendas son preparadas especialmente. Se dice que es la Ki’ichpam Màama (la Virgen María) quien guía las almas de los niños difuntos. Yuum Kimil, la figura maya de la muerte, es la entidad quien acompaña a las almas de los adultos. ${ }^{67}$

A diferencia de lo que sucede en Huicalo, para los mayas yucatecos, Kimil es la entidad que pasa las almas de los adultos durante el Hanal pixan; y la Virgen María pasa las almas de los niños; con todo y esta discrepancia, existe una relación conceptual directa entre el Kimil de la historia y el Kimil de los Kopchén. En cuanto a la apariencia física, Le Guen no describe al Kimil de los mayas yucatecos; sin embargo, se sabe que tiene aspecto de esqueleto debido a que, en el altar, le colocan of rendas especiales para que tarde en comer. «Los informantes señalan que las ofrendas dedicadas a esta entidad son cosas que se comen muy lentamente (huevo con cáscara, pata de gallina), pues la Muerte es muy ts'ík («brava») y cuando termina de comer, se lleva a las almas». ${ }^{68}$ Con el objetivo de que Kimil no se lleve a las almas tan rápido, y suponiendo que tiene aspecto de esqueleto, «... se le ofrecen a la Muerte alimentos difíciles de manipular, toda vez que Yuum Kimil tiene el aspecto de un esqueleto y suponiendo

\footnotetext{
${ }^{65}$ Ibid., p. 87.

${ }^{66}$ Ibid., p. 89.

${ }^{67}$ Ibid., p. 90.

68 Idem.
} 
que tomara el huevo entre sus falanges, éste caería en su recipiente varias veces antes de lograr comerlo». ${ }^{69}$ Este aspecto esquelético es otro punto de convergencia del Kimil Kopchén con la versión antropomórfica de Kimil en Huicalo.

\section{La muerte y sus imaginarios: hibridación y mestizaje}

Hay dos aspectos que analizar para entender la manera en la que los referentes anteriormente descritos se migran, se reintegran e hibridan en la gráfica y concepto de Huicalo: primero, el atractor de toda esa serie de imágenes es la idea del psicopompo como una entidad que acompaña al alma de los muertos en su tránsito de un mundo a otro. Segundo, el psicopompo, como atractor, permite que las diversas imágenes, procedentes del imaginario de la muerte, en su proceso de reelaboración y adaptación, tomen sentido y se mezclen tanto en Kimen como en Kimil. Explicaremos a qué nos referimos en los párrafos siguientes.

Recordemos que retomamos el concepto de hibridación de Canclini, que propone que la hibridación se da cuando se generan nuevas estructuras o prácticas derivadas de la fusión, no sin contradicciones, de estructuras o prácticas que existían de formas separadas. ${ }^{70}$ Si retomamos este concepto, de entrada sabemos que habrá aspectos que no logran fusionarse porque generan conflicto, pero ¿¿de qué manera se da esa fusión? Tiene que ser a partir de puntos de convergencia o enlace. Para entender la manera en la que se lleva a cabo la hibridación de imaginarios en Huicalo, es necesario que retomomemos la noción de atractor o aglutinante que propone Serge Gruzinski en su libro El pensamiento mestizo, cultura amerindia y civilización del Renacimiento, ${ }^{71}$ para quien existen relaciones aún entre los reinos que parecieran más lejanos y diferentes. Expresa que «lo híbrido también es el resultado espectacular de una "simpatía" en el seno de un universo lleno de uniones y de enfrentamientos». ${ }^{72}$ Lo que consigue la proximidad y asociación entre estos mundos lejanos es ese concepto aglutinante, esa especie de «atractor» que "al reorganizar y dar sentido a piezas dispares, permite que estas se ajusten entre sím. ${ }^{73} \mathrm{E} 1$ psicopompo, como una entidad que pasa las almas de los muertos de un mundo al otro, es ese aglutinante que permite la fusión e hibridación en las figuras de Kimen —shinigami, parca y catrina— y Kimil — personifición de la muerte, Kimil maya y dragón japonés-. La hibridación entre los diferentes elementos que componen a este personaje se da porque todos son imaginarios cuyo esquema es la muerte.

\footnotetext{
69 Idem.

70 García Canclini, N. Op.cit., p. III.

${ }^{71}$ Gruzinski, S. El pensamiento Mestizo, cultura amerindia y civilización del Renacimiento. Barcelona, Paidós, 2007.

72 Ibid., p. 213.

73 Ibid., p. 235.
} 
Por otro lado, el concepto de esquema propuesto por Durand es la prolongación cultural de las dominantes reflejas ${ }^{74}$ que todo ser humano necesita satisfacer para subsistir. El esquema es «una generalización dinámica y afectiva de la imagen, constituye la facticidad y la no sustantividad general del imaginario [...]. Él hace la unión entre la imagen y los gestos inconscientes de la sensoriomotricidad, entre dominantes reflejas y representaciones. ${ }^{75}$

En este artículo proponemos la idea de la muerte como el esquema, cuya prolongación cultural toma la forma de un ente abstracto, que van a entender de manera diferente las culturas y sociedades a lo largo del tiempo. El esquema sería entonces la muerte y el arquetipo, o sea, el intermediario «entre los esquemas subjetivos y las imágenes suministradas por el entorno perceptivo», ${ }^{76}$ sería la figuración de la misma en un ente que cumple la función de psicopompo. Tanto esquemas como arquetipos se materializan en realidades físicas y mentales llamadas imágenes o imaginados ${ }^{77}$ las cuales, en nuestro caso, son la fuente primaria que analizamos en Huicalo.

La manera en la que en Huicalo se lleva a cabo el procesos de hibridación implica retomar imágenes procedentes del esquema de la muerte, las cuales, a su vez, proceden de diferentes procesos de mestizaje/hibridación y adaptaciones a diversos contextos. Lo que Huicalo retoma es, justamente, esa diversidad de imágenes procedentes de diferentes temporalidades y espacios, que se integran teniendo como concepto atractor o aglutinante al psicopompo. A partir de dichas imágenes se lleva a cabo una reelaboración adaptada a la nueva historia.

De entrada, el propio tiempo y espacio en los que se sitúa la historia corresponden ya a varios procesos de mestizaje: la mezcla de la tradición prehispánica ${ }^{78}$ con el día de todos los santos ${ }^{79}$ y las danzas de la muerte occidentales. Se trata del día de muertos,

${ }^{74}$ La necesidad de mantenerse erguido, nutrición y reproducción.

75 Durand, G. Op. cit., p. 62.

76 Ibid., p. 63.

77 Cano Vargas, A. «De la historia de las mentalidades», en Ciencias sociales y educación, vol. 1, n. ${ }^{\circ}$ 1, (2012), p. 141.

${ }^{78}$ Hubo traslapes temporales, temáticos y simbólicos, en relación a festejos de muertos, tanto en el mundo prehispánico como en Europa. Durante la conquista, fue evidente que había algunos festejos prehispánicos, con coincidían en tiempo con los europeos, como el de Todos Santos con las ceremonias del mes de quecholli. INAH. Calmecac Xochipilli. Disponible en https://www.youtube. com/watch?v=VAWf6q7qrRs

79 Promovido en el siglo xi por el Abad Cluny, Todos santos se celebraba el primero de noviembre, ese día las iglesias y santuarios exhibirían sus reliquias las cuales otorgaban a la gente el perdón de sus pecados a cambio de plegarias. Malvido E. «La festividad de Todos Santos, fieles difuntos y su altar de muertos en México, patrimonio intangible de la humanidad», en La festividad indígena dedicada a los muertos en México, patrimonio cultural y turismo, cuadernos. México, CONACULTA, 2006, pp. 41-56. 
reelaborado y transformado de acuerdo al contexto, que la autora ve en su dinámica inmediata y en su cultura visual, ${ }^{80}$ lo que la lleva a retomar tradiciones ya híbridas y mezclarlas con imágenes procedentes de divesos contextos y temporalidades, las cuales, a vez, vuelve a mezclar para dar sentido a su narración.

Kimen es un catrín que, además, va a retomar imágenes de la indumentaria de la personificación actual de la muerte en los medios de masas, lo que se da debido a que «el mito va a pervivir y reubicarse, aunque sea como indica Eliade bajo una forma degradada o camuflada, en diferentes ámbitos de la vida cotidiana contemporánea; en una perfecta simbiosis con el desarrollo tecnológico». ${ }^{81}$

Catrín, calavera de azúcar, shinigami, parca, se mezclan con lo original del personaje, y representan un fenómeno de adaptación en movimiento, en donde unos aspectos se mezclan y otros entran en conflicto: «... lo que predomina en la naturaleza y en nuestro medio es la nube, una forma desesperadamente compleja, vaga, cambiante, fluctuante y siempre en movimiento». ${ }^{82}$

En Huicalo, las imágenes del imaginario de la muerte flotan en la nube de la cultura visual de Emma Delgado mediante referentes de contextos dispersos, que encuentran a su concepto aglutinante o atractor en la idea del psicopompo. El aglutinante es el psicopompo, concepto que permite la mezcla y proceso de traslape entre los referentes que integran, tanto conceptual como gráficamente, a Kimen y a Kimil; los ordena, busca esa simpatía a partir de la cual estos conceptos de un mismo imaginario, pero procedentes de diversos contextos, se engarzan y mutan en algo nuevo; permite la hibridación de formas y la creación de nuevos productos.

Pero, si bien el atractor es el encargado de encontrar esas simpatías que permiten el proceso de hibridación, no todos los elementos de los imaginarios se integran en la nueva forma. Para Canclini, la «hibridación no es sinónimo de fusión sin contradicciones, sino que puede ayudar a dar cuenta de las formas particulares de conflicto generadas en la interculturalidad reciente»; ${ }^{83}$ conflicto que se observa en el ámbito conceptual de Kimil en su forma ofidia ya que, si bien el dragón oriental y el prehispánico tienen puntos de convergencia conceptual relacionados con la idea de opuestos complementario, la manera en que la hibridación se lleva a cabo en Huicalo se

80 Se relaciona con una cultura en la que las imágenes son elementos centrales de la representación del mundo en el sentido de formulación. Alpers, S. «Cuestionario sobre cultura visual» en October, n. ${ }^{\circ}$ 77 (1996). Cada cultura tiene su propia tradición visual surgida de una interpretación particular de la realidad. Renobell, $V$. «Hipervisualidad. La imagen fotográfica en la sociedad del conocimiento y la comunicación digital», en Revista sobre la sociedad del conocimiento, n. 1 (1996).

81 Carretero Pasín, Á. E. «La persistencia del mito de lo imaginario en la cultura contemporánea», en Política y sociedad (2006), p. 121.

82 Gruzinski, S. Op. cit., p. 70.

83 García Canclini, N. Op. cit., p. II. 
orienta a los opuestos irreconciliables. Lo anterior, implica que la complementariedad de luz-oscuridad se desecha y la lógica permenece desde la perspectiva occidental.

La diferencia se expresa, pues, en la lógica. La de la contradicción (que imposibilita el ser y su negación en el mismo tiempo y sentido) gobierna el origen (no dualista) del pensar que se instaura en Grecia; la basada en la contrariedad superada (que posibilita una cosa y su contraria como otra) se instaura a la hora de explicar el origen (no dualista) en el oriente. ${ }^{84}$

Tanto el dragón prehispánico como el oriental responden conceptualmente a la lógica de la contrariedad superada, en la que los opuestos no son irreconciliables, sino complementarios y la base de todo lo existente. En Huicalo, la lógica que impera es la contradicción de origen, en la cual «no es posible que una cosa sea y no sea a la vez en un mismo sentido. No es posible una cosa y la negación de la misma». ${ }^{85}$

Lo anterior hace que Kimil, que en su origen debiera mostrar tanto aspectos benignos como malignos, tome únicamente la función de villano en el relato y se torne en una entidad completamente maligna e inframundana a la que Kimen y Aruba derrotan con ayuda de los rezos de la madre de la niña, de la misma manera que en el cristianismo se derrota al demonio mendiante rezos, velas y encomiendas al Dios cristiano. Este es el desgarramiento que se da en el proceso de hibridación, esta parte conceptual en donde la complementariedad entra en conflicto con la oposición total, debido a que el atractor «... selecciona una u otra conexión, reorienta uno $\mathrm{u}$ otro enlace, o sugiere una u otra asociación entre los seres y las cosas. Interviene como si estuviese dotado de una energía propia». ${ }^{86}$ Así como se seleccionaron puntos gráficos de convergencia, se descartan los conflictos y con ello la lógica de complementariedad. Prevalece el referente más cercano: la oposición total propia del cristianismo.

\section{Conclusiones}

En este artículo, argumentamos que la historieta Huicalo hibrida elementos del manga japonés en dos aspectos: formato e imaginarios mágico-religiosos; en estos últimos, la figura de la muerte se crea teniendo como concepto atractor al psicopompo. Lo anterior resulta no en una mera réplica, ni de la estrategia de mercado (media mix), ni de su forma narrativa (cross media), ni de los personajes en los que se basa, sino en un proceso de hibridación en el que la autora retoma elementos dispersos en su medio y cultura visual, los adapta a sus posibilidades y a su contexto para crear un nuevo producto.

${ }^{84}$ LÁzaro Pulido, M. «Japón-Cristianismo: dos lógicas diferenciadas, un mismo ser humano. Diálogo interreligioso en la nueva civilización del siglo xxI» en Cauriensia, vol.5 (2010), p. 99.

85 Ibid., p. 98.

${ }^{86}$ Gruzinski, S. Op. cit., p. 237. 
La hibridación en Huicalo se da desde dos vertientes: el formato y la estrategia de mercado, y los imaginarios de la muerte, los cuales, a partir de asimilaciones, adaptaciones y fusiones resultan siempre en un cómic, el cual únicamente cambia de un medio impreso a una plataforma digital. En este sentido, Huicalo y sus productos relacionados no presentan derivaciones en otros medios audiovisuales y electrónicos, es un producto creado a partir de la creatividad y esfuerzo personal e individual de la autora, de ninguna manera estamos hablando de las grandes industrias que distribuyen sus productos de manera masiva.

Dado que una parte importante del proceso de hibridación en Huicalo se da por medio de los imaginarios, en esta investigación nos centramos en el imaginario de la muerte, el cual proviene de sucesivas transformaciones y mezclas. Kimen y Kimil representan esas metamorfosis, por medio de las cuales los referentes se mezclan y resignifican, conceptos aparentemente caóticos por su diversidad espacial y temporal de origen, los cuales se aglutinan a través de la idea de una entidad que pasa almas de un mundo al otro, el atractor.

Huicalo resulta una historieta muy interesante de analizar por diversos aspectos, su formato, estrategia de venta, distribución, productos derivados y narrativa, en la cual se mueven personajes originales que, sin embargo, integran dentro de sí un amplio bagaje de imaginarios producto de la multiculturalidad e hibridación cultural, muy evidentes en la época contemporánea. 


\section{BibLiografíA}

Alpers, S. «Cuestionario sobre cultura visual», en October, n. 77 (1996).

Bartra, A. «Piel de papel. Los Pepines en las educación sentimental del mexicano", en Hacia Otra Historia del arte en México, la fabricación del arte nacional a debate (1920-1950). México, CONACULTA, 2002, pp. 139-141.

Bouissou, J. M. Manga. Historie et univers de la bande desinée japonaise. París, Philippe Picquier, 2010.

Camacho Morfín, T. y González Manrique, M. J. «Las calaveras de Posada. De las Danzas de la muerte a las Vanitas», en Trayectos, usos y significaciones de la imagen y la memoria. Puebla, Benemérita Universidad Autónoma de Puebla, 2017, pp. $172-173$.

Cano Vargas, A. «De la historia de las mentalidades», en Ciencias sociales y educación, vol. 1, n. ${ }^{\circ}$ 1, (2012), pp. 135-146.

Carretero Pasín, Á. E. «La persistencia del mito de lo imaginario en la cultura contemporánea», en Politica y sociedad (2006), pp. 107-126.

Castelli Olvera, S. I. Entrevista realizada a Nicolás Magaña. Ciudad de México (23 de septiembre 2016).

De la Garza, M. «El dragón, símbolo por excelencia de la vida y muerte entre los mayas», en Estudios de cultura maya, vol. 20 (1999), pp. 179-207.

Durand, G. Las estructuras antropológicas de lo imaginario. Madrid, Fondo de Cultura Económica, 2008.

García Canclini, N. Culturas híbridas. México, Mondadori, 2009.

Ginzburg, C. Mitos, emblemas e indicios, morfología e historia. Barcelona, Gedisa, 1999.

Gruzinski, S. El pensamiento mestizo, cultura amerindia y civilización del Renacimiento. Barcelona, Paidós, 2007.

Guerrero Viguri, R. «Catalina Creel, la versión contemporánea de la Catrina», en Balajú, Revista de cultura y comunicación, n. ${ }^{\circ} 3$ (2015), pp. 62-71. 
Hernández-PÉrez, M. Manga, anime y videojuego. Narrativa cross media japonesa. Zaragoza, Universidad de Zaragoza, 2017.

INAH. Calmecac Xochipilli. Disponible en https:/www.youtube.com/watch?v=VAWf6q7qrRs

Labarga, F. «Reseña de Vanitas», en «Retórica visual de la mirada de Luis Vives-Ferrándiz Sánchez», en Anuario de Historia de la Iglesia, vol. 21 (2012), p. 626.

LÁzaro Pulido, M. «Japón-Cristianismo: dos lógicas diferenciadas, un mismo ser humano. Diálogo interreligioso en la nueva civilización del siglo xxI», en Cauriensia, vol. 5 (2010), pp. 93-131.

Le Guen, O. «Ubèel Pixan: el camino de las almas. Ancestros, familiares y colectivos entre los mayas yucatecos», en Península vol. 3, n. 1 (2008), pp. 83-120.

Malvido E. «La festividad de Todos Santos, fieles difuntos y su altar de muertos en México, patrimonio intangible de la humanidad», en La festividad indigena dedicada a los muertos en México, patrimonio cultural y turismo, cuadernos. México, CONACULTA, 2006, pp. 41-56.

Morales Damián, M. A. «Muerte fecunda. Imágenes de Ah Kimil en el Códice Madrid», en Congreso Internacional Imágenes de la Muerte (Salta, agosto de 2014). Argentina, Universidad Nacional de Salta, 2014.

Moreno Griñón, S. «Death Note: el concepto de Shinigami y la pena de muerte en Japón», en Brumal, revista de investigación sobre lo fantástico, vol. vi, n. 1 (2018), pp. 243-261.

Pérez Miranda, I. «Hijas de la noche II: El destino de las parcas entre el pasado y el presente», en Arys, n. 8 (2009-2010), pp. 129-140.

Renobell, V. «Hipervisualidad. La imagen fotográfica en la sociedad del conocimiento y la comunicación digital», en Revista sobre la sociedad del conocimiento, n. ${ }^{\circ}$ 1 (1996).

S.a. «Breve historia de las calaveritas de azúcar», en Regeneración (1 de noviembre de 2016). Disponible en https://regeneracion.mx/breve-historia-de-las-calaveritas-de-azucar/

Santiago Iglesias, J. A. Manga, del cuadro flotante a la viñeta japonesa, Pontevedra, Grupo de Investigación dX5 Digital y grafic art research, 2010. 
Valle Morán, M. «La figura del psicopompo en las prácticas y rituales contemporáneos de tránsito hacia la muerte», en XII Congreso español de sociología, 2016. Disponible en https://www.fes-sociologia.com/la-figura-del-psicopompo-en-las-practicas-y-rituales-contemporaneos/congress-papers/2915/

Zhaо, Q. A study of dragons, East and West. Nueva York, Peter Lang, 1992. 